\title{
Variação do Tamanho de Sementes de Plantas Daninhas e sua InfluênCIA nOS PadRões de Emergência das Plântulas ${ }^{1}$
}

\author{
Weed Seed Size Variation and Its Influence on Seedling Emergence Patterns
}

\author{
ARALDI, R. ${ }^{2}$, VELINI, E.D. ${ }^{3}$, GOMES, G.L.G.C. ${ }^{3}$, CARBONARI, C.A. ${ }^{2}$, ALVES, E. ${ }^{5}$ e \\ TRINDADE, M.L.B. ${ }^{4}$
}

\begin{abstract}
RESUMO - Estudos relacionados ao tamanho de sementes e sua influência no processo germinativo de plantas daninhas são necessários devido à grande importância das espécies e à escassez de informações relacionadas à produção de sementes dessas plantas. Dessa forma, este trabalho objetivou estudar a variação do tamanho de sementes de 12 espécies de plantas daninhas e a emergência de duas dessas espécies semeadas em diferentes profundidades. Foi mensurado o peso unitário de 200 sementes por espécie de planta daninha selecionada e estabelecidas curvas de distribuição das frequências não acumuladas para o peso das sementes das espécies, utilizando-se o modelo de Gompertz. Após a classificação por tamanho (pequenas, médias e grandes), sementes de Ipomoea purpurea e Brachiaria decumbens foram semeadas em campo, em canteiros de 1,2 $\mathrm{m}^{2}$, em diferentes profundidades no solo $(2,4,6,8$ e $10 \mathrm{~cm}$ ) de cada tratamento (profundidade); efetuaram-se quatro repetições. De maneira geral, no primeiro estudo, os resultados indicaram que não há como se referir ao peso de sementes das espécies de plantas daninhas estudadas considerando-se apenas a média dessa característica, devido à variação que pode ser encontrada. Essa grande variação no tamanho das sementes pode estar associada, também, a variações nos padrões de emergência, o que foi verificado no segundo estudo para a espécie I. purpurea. O índice de velocidade de emergência para $I$. purpurea foi maior para $4 \mathrm{~cm}$ de profundidade nas sementes pequenas, $8 \mathrm{~cm}$ nas sementes médias e de 6 a $10 \mathrm{~cm}$ de profundidade nas sementes grandes.
\end{abstract}

Palavras-chave: biologia, distribuição de frequências, Ipomoea purpurea, Brachiaria decumbens.

\begin{abstract}
Studies on seed size and its influence on the process of weed germination are needed because of the importance of the species and scarcity of information regarding these plants' seed production. Thus, this study aimed to investigate the seed size variation of twelve weed species and the emergence of two of these species planted at different depths. The unit weight of 200 seeds was measured perweed species selected and non-accumulated frequency distribution curves were established for the weight of the species seeds, using the Gompertz model. After classification based on size (small, medium, and large) seeds of Ipomoea purpurea and Brachiaria decumbens were sown in field plots of $1.2 \mathrm{~m}^{2}$ at different soil depths $(2,4,6,8$, and $10 \mathrm{~cm}$ ) of each treatment (depth); four repetitions were carried out. In general, the first study's results indicated that one cannot refer to the weight of the seeds of the weed species studied considering only the mean of this feature, due to the large variation that can be found. This great variation in seed size may be associated with variations in the emergence patterns, verified in the second study on the species I. purpurea. The emergence speed index of $\boldsymbol{I}$. purpurea was greater at $4 \mathrm{~cm}$ depth in the small seeds, $8 \mathrm{~cm}$, in the medium seeds and from 6 to $10 \mathrm{~cm}$ depth in the large seeds.
\end{abstract}

Keywords: biology, frequency distribution, Ipomoea purpurea, Brachiaria decumbens.

Recebido para publicação em 27.6.2011 e aprovado em 14.7.2012

2 Pós-Graduação em Agronomia pela Faculdade de Ciências Agronômicas - FCA/UNESP, Campus de Botucatu, Fazenda Experimental Lageado, Caixa Postal 237, 18603-970 Botucatu-SP, <araldi@fca.unesp.br>; ${ }^{2}$ Professores, Dr., Dep. de Agricultura, FCA/UNESP, Campus de Botucatu; ${ }^{3}$ Pesquisadora, FCA/UNESP, Campus de Botucatu, Núcleo de Pesquisa Avançada em Matologia - NUPAM; ${ }^{4}$ Professora, Dra., Faculdade de Agronomia, UNESP, Campus de Registro. 


\section{INTRODUÇÃO}

A competição é um dos principais fatores de interferência das plantas daninhas na produção final das plantas cultivadas. A capacidade de sobrevivência em condições adversas é uma das características que conferem às plantas daninhas alta competitividade (Thompson et al., 1993).

Entre as características das plantas daninhas que explicam a grande disseminação de suas sementes, destaca-se a eficiência reprodutiva. Balbinot Jr. et al. (2002) afirmam que a maioria das plantas daninhas que infestam áreas agrícolas reproduz-se sexuadamente, ou seja, através da formação de sementes. Essa capacidade das plantas daninhas de produzir sementes, em quantidade e formas diferentes, é variável e está diretamente relacionada à família, ao gênero e até mesmo à espécie. Essa capacidade produtiva também sofre ação do ambiente no qual essa planta está inserida. Quando as condições ambientais são favoráveis, as plantas daninhas produzem grande número de sementes, sendo essa quantidade definida pelas suas características genéticas (Fontes, 2005).

Além da quantidade, o tamanho das sementes produzidas também pode ser influenciado pelas condições ambientais; dessa forma, há possibilidade de produção de sementes com diferentes tamanhos em uma mesma espécie de planta daninha. As variações no tamanho e na qualidade fisiológica da semente, segundo Bean (1973), são inevitáveis para a planta progenitora quando esta se encontra sob a influência das oscilações ambientais.

Estudos têm sido conduzidos visando identificar diferenças qualitativas em sementes. Andrade et al. (1998), estudando sementes de milho, e Fantinatti et al. (2001) sementes de feijão, observaram diferenças significativas quando compararam sementes de diferentes tamanhos, influenciando a uniformidade do estande das plantas e a produção de sementes ou grãos.

Mesmo dentro de populações de uma mesma espécie, porém originadas de comunidades submetidas a diferentes graus de interferência, o tamanho médio da semente mostrase diferente, como demonstram os estudos de
Werner \& Platt (1976) com Solidago sempervirens e de Solbrig \& Simpson (1974) com Taraxacum officinale, e as populações dos estádios iniciais apresentaram sementes mais pesadas do que as das populações dos estádios finais.

O tamanho de sementes é uma característica morfológica que pode influenciar também na seletividade de herbicidas aplicados em pré-emergência, visto que sementes de menor tamanho adquirem teores de água superiores aos observados em sementes de maior tamanho, o que está relacionado à maior área de contato por unidade de massa, nas sementes menores (Souza, 1996). Em trabalho realizado por Rosenthal et al. (2006) com sementes de milho, foi observado que as sementes de menor tamanho originaram plantas com sintomas mais severos de intoxicação quando utilizado o herbicida S-metolachlor em pré-emergência.

Em relação à distribuição das sementes de plantas daninhas no solo, elas estão distribuídas até cerca de $20 \mathrm{~cm}$ de profundidade. A profundidade no solo em que uma plântula é capaz de germinar e produzir uma plântula normal é variável entre as espécies e apresenta importância ecológica e agronômica (Guimarães et al., 2002). Em trabalho conduzido por Oliveira Jr. \& Delistoianov (1996), sementes de Desmodium purpureum foram colocadas em diversas profundidades, concluindo-se que nas profundidades em que houve emergência das plântulas, até $3,75 \mathrm{~cm}$, o processo ocorreu de forma rápida e concentrada entre o quarto e o décimo dia após a semeadura.

Ghorbani et al. (1999) observaram que as plântulas de Amaranthus retroflexus tiveram maior emergência na semeadura a 0,5 e $3,0 \mathrm{~cm}$. As sementes colocadas na superficie do solo e a $4 \mathrm{~cm}$ de profundidade tiveram emergência de plântulas reduzida. Já Dias Filho (1996) avaliou a emergência de plântulas de Ipomoea asarifolia semeadas em profundidades de 0 a $10 \mathrm{~cm}$ e observou tendência de que sementes colocadas na superficie do solo tivessem menor emergência, o que também foi atribuído à pequena área de contato entre o solo e as sementes e ao ressecamento da superficie deste.

Segundo Toledo et al. (1993) e Shen et al. (2005), plântulas de Xanthium strumarium e 
Alternanthera philoxeroides podem emergir de até $18 \mathrm{~cm}$ de profundidade. Isso possibilita a essas espécies maior capacidade de sobrevivência em áreas com perturbações por tratos culturais, podendo também ter implicações importantes relacionadas ao seu controle por herbicidas aplicados ao solo.

Há evidências (Fausey \& Renner, 1997; Brighenti et al., 2003) de que a emergência de sementes de plantas daninhas, como Cardiospermum halicacabum, Bidens pilosa, Setaria faberi e Panicum dichotomiflorum, seja maior quando elas são posicionadas entre 1 e $5 \mathrm{~cm}$ de profundidade, embora possa haver algum nivel de emergência em profundidades de até $12 \mathrm{~cm}$.

Yamashita et al. (2005), trabalhando com sementes de picão-preto e fedegoso, encontraram para o primeiro maior emergência de plântulas em relação ao último, exceto a $10 \mathrm{~cm}$ de profundidade. Isso evidencia a capacidade do fedegoso de emergir quando suas sementes germinam a maiores distâncias da superfície.

Considerando as interferências impostas às culturas pelas plantas daninhas, principalmente a competição, e que a quantidade de informações sobre sementes é reduzida, há necessidade de estudos básicos relacionados à biologia dessas espécies daninhas, visto que o conhecimento da dinâmica das plantas daninhas envolve estudos relacionados ao tamanho de sementes destas.

Dessa forma, os objetivos deste trabalho foram identificar as possiveis variações no tamanho das sementes de 12 espécies de plantas daninhas e avaliar a emergência de duas dessas espécies, com diferentes tamanhos de sementes e submetidas a cinco profundidades de semeadura.

\section{MATERIAL E MÉTODOS}

$\mathrm{Na}$ parte inicial do trabalho foram estudadas 12 plantas daninhas, distribuídas em seis famílias e sete gêneros distintos: família Convolvulaceae - gênero Ipomoea, espécies estudadas: Ipomoea grandifolia, Ipomoea quamoclit, Ipomoea hederifolia, Ipomoea purpurea e Ipomoea nil; família Poaceae gênero Brachiaria, espécies estudadas: Brachiaria decumbens e Brachiaria plantaginea
- gênero Cenchrus, espécie estudada: Cenchrus echinatus; família Commelinaceae - gênero Commelina, espécie estudada: Commelina benghalensis; família Euphorbiaceae - gênero Euphorbia, espécie estudada: Euphorbia heterophylla; família Lamiaceae - gênero Leonotis, espécie estudada: Leonotis nepetaefolia; e familia Asteraceae - gênero Bidens, espécie estudada: Bidens pilosa.

As mensurações foram realizadas com a avaliação de 200 sementes de cada uma das 12 espécies de plantas daninhas. Para essa análise qualitativa, utilizou-se balança digital com precisão de quatro casas decimais. Após obtenção de todos as dados relativos ao peso unitário das sementes, foram elaboradas curvas de distribuição de frequências não acumuladas para o peso das sementes variável essa que possibilita a determinação da uniformidade de distribuição dos dados. A construção das curvas de frequência foi baseada no modelo de Gompertz:

$$
\mathrm{FNA}=\mathrm{c}^{*} \mathrm{e}^{\wedge}\left(\mathrm{a}-\mathrm{bc} \mathrm{c}^{*} \mathrm{X}-\mathrm{e}^{\wedge}\left(-\mathrm{b}-\mathrm{c}^{*} \mathrm{X}\right)\right),
$$

em que a, b e c correspondem aos parâmetros da equação. O deslocamento da curva ao longo do eixo x é representado pelo módulo do parâmetro "b", e a inclinação ou concavidade da curva em relação à frequência acumulada, pelo parâmetro "c" (Velini, 1995).

Para melhor visualização dos resultados, optou-se por apresentar as frequências não acumuladas que correspondem à derivada primeira do modelo e que permitem a interpretação biológica dos resultados obtidos neste trabalho. Foram determinadas, também com base no modelo de Gompertz, as medidas de posição (moda, média e mediana) e de dispersão (amplitude, variância, desvio-padrão, coeficientes de curtose e assimetria, nivel de confiança e coeficiente de variação) dos dados analisados. A precisão do ajuste dos dados no modelo de Gompertz foi avaliada pelos coeficientes de determinação $\left(R^{2}\right)$ das equações.

Após a análise, selecionaram-se duas espécies daninhas para o estudo de emergência. Sementes de Ipomoea purpurea e Brachiaria decumbens foram classificadas em pequenas, médias e grandes. A classificação foi obtida através da pesagem unitária das sementes, e a semeadura foi realizada em canteiros de 
$1,2 \mathrm{~m}^{2}$, no campo. Foram montadas 24 parcelas (canteiros) em quatro blocos, sendo duas espécies de plantas daninhas, três tamanhos de sementes e quatro repetições. Os canteiros tinham cinco linhas de semeaduras, e cada linha representava uma profundidade diferente. As profundidades utilizadas foram de 2, 4, 6,8 e $10 \mathrm{~cm}$. Foram colocadas 12 sementes por linha (profundidade). O trabalho foi conduzido por 28 dias após a semeadura nos canteiros, sendo avaliada a emergência das sementes de dois em dois dias.

Os dados coletados para I. purpurea e $B$. decumbens foram acumulados e processados em porcentagem do total de sementes utilizadas para a semeadura, e o ajuste foi pela análise linear de regressão. Foi analisado o indice de velocidade de emergência (IVE) para as sementes pequenas, médias e grandes em cada profundidade das espécies em estudo. Os dados foram submetidos a análise de variância, sendo as médias comparadas pelo teste $t$ $(\mathrm{p}<0,10)$. Os dados da diferença mínima significativa (DMS) foram representados nos gráficos de IVE.

\section{RESULTADOS E DISCUSSÃO}

Os valores para as medidas de posição e de dispersão obtidas a partir da utilização do modelo de Gompertz são apresentados nas Tabelas 1, 2 e 3. Para todas as espécies estudadas, os coeficientes de determinação $\left(R^{2}\right)$ foram superiores a 0,97 , indicando a grande precisão dos ajustes efetuados entre as frequências não acumuladas (expressa em porcentagem) e o peso das sementes analisadas, com a utilização do modelo de Gompertz.

Os resultados das análises de regressão, obtidas com o modelo, encontram-se nas Figuras 1 a 3 . A concavidade das curvas construídas, representada pela curtose, demonstra a uniformidade das amostras; quanto mais plana a curva, maior é a frequência de valores extremos, caracterizando maior variabilidade com relação ao tamanho das sementes formadas por aquela população considerada.

Na Figura 1, verifica-se que a distribuição das frequências não acumuladas é assimétrica para as duas espécies do gênero Brachiaria; dessa forma, os valores de média, mediana e moda são diferentes entre si.
Observa-se que, para $B$. decumbens, a assimetria é negativa; os valores de média e de mediana estão à esquerda da moda, portanto inferiores ao valor modal (valor de maior frequência na amostra). Com esses resultados, verifica-se que há maior variabilidade para sementes pequenas em relação às grandes. Já para B. plantaginea tem-se a assimetria positiva, com os valores de média e mediana à direita da moda, predominando maior variabilidade para sementes maiores em relação às menores na curva de distribuição da frequência (Figura 1).

Os valores modais de $0,0087 \mathrm{~g}$ para $B$. decumbens e 0,0012 g para B. plantaginea indicam que as sementes de $B$. decumbens formadas, com maior frequência, são aproximadamente sete vezes maiores que as de B. plantaginea. A variação entre a semente formada com maior e com menor peso (amplitude) é da ordem de, aproximadamente, duas vezes e meia para $B$. decumbens e nove vezes para $B$. plantaginea.

De maneira geral, as sementes de B. plantaginea apresentaram maiores valores

Tabela 1 - Resultados das análises de regressão das freqüências não acumuladas do peso de sementes de Brachiaria decumbens e Brachiaria plantaginea, utilizando o modelo de Gompertz, bem como as médias, modas e medianas (g). Botucatu-SP, 2011

\begin{tabular}{|c|c|c|c|}
\hline \multirow{2}{*}{\multicolumn{2}{|c|}{ Modelo }} & \multicolumn{2}{|c|}{ Espécie } \\
\hline & & \multirow{2}{*}{$\begin{array}{c}\begin{array}{c}\text { Brachiaria } \\
\text { decumbens }\end{array} \\
4,6052\end{array}$} & \multirow{2}{*}{$\begin{array}{c}\begin{array}{c}\text { Brachiaria } \\
\text { plantaginea }\end{array} \\
4,6052\end{array}$} \\
\hline \multirow{3}{*}{$\begin{array}{l}\text { Estimativas dos } \\
\text { parâmetros }\end{array}$} & A & & \\
\hline & B & $-8,2944$ & $-2,0209$ \\
\hline & $\mathrm{C}$ & $1.041,3300$ & $1.412,8700$ \\
\hline \multicolumn{2}{|l|}{$\mathrm{R}^{2}$} & 0,9722 & 0,9766 \\
\hline \multicolumn{2}{|c|}{ Coeficiente de curtose } & 3,2910 & 3,7271 \\
\hline \multicolumn{2}{|c|}{ Coeficiente de assimetria } & $-0,4719$ & 1,2733 \\
\hline \multicolumn{2}{|l|}{ Mínimo } & 0,0045 & 0,0007 \\
\hline \multicolumn{2}{|l|}{ Máximo } & 0,0110 & 0,0055 \\
\hline \multicolumn{2}{|l|}{ Média } & 0,0083 & 0,0020 \\
\hline \multicolumn{2}{|l|}{ Mediana } & 0,0084 & 0,0017 \\
\hline \multicolumn{2}{|l|}{ Moda } & 0,0087 & 0,0012 \\
\hline \multicolumn{2}{|l|}{ Variância da amostra } & $1,18 \cdot 10^{-06}$ & $1,28 \cdot 10^{-06}$ \\
\hline \multicolumn{2}{|l|}{ Desvio-padrão } & 0,00108 & 0,00113 \\
\hline \multicolumn{2}{|l|}{ Erro-padrão } & $7,69 \cdot 10^{-05}$ & $8,01 \cdot 10^{-05}$ \\
\hline \multicolumn{2}{|c|}{ IC $\mathrm{p}<0,005$ limite superior } & 0,00845 & 0,00216 \\
\hline \multicolumn{2}{|c|}{ IC $\mathrm{p}<0,005$ limite inferior } & 0,00814 & 0,00184 \\
\hline
\end{tabular}


Variação do tamanho de sementes de plantas daninhas e sua ...

Tabela 2 - Resultados das análises de regressão das frequências não acumuladas do peso de sementes de cinco espécies de Ipomoea (Ipomoea nil, I. grandifolia, I. quamoclit, I. hederifolia e I. purpurea), utilizando o modelo de Gompertz, bem como as médias, modas e medianas (g). Botucatu-SP, 2011

\begin{tabular}{|c|c|c|c|c|c|c|}
\hline \multirow{2}{*}{\multicolumn{2}{|c|}{ Modelo }} & \multicolumn{5}{|c|}{ Espécie } \\
\hline & & I. nil & I. grandifolia & I. quamoclit & I. hederifolia & I. purpurea \\
\hline \multirow{3}{*}{$\begin{array}{c}\text { Estimativas dos } \\
\text { parâmetros }\end{array}$} & A & 4,6051 & 4,6051 & 4,6051 & 4,6051 & 4,6051 \\
\hline & $\mathrm{B}$ & $-7,9616$ & $-7,9560$ & $-8,5936$ & $-6,3257$ & $-5,5388$ \\
\hline & $\mathrm{C}$ & 362,1000 & 728,9700 & 780,9300 & 454,3400 & 344,8500 \\
\hline \multicolumn{2}{|l|}{$\mathrm{R}^{2}$} & 0,9971 & 0,9943 & 0,9972 & 0,9860 & 0,9919 \\
\hline \multicolumn{2}{|c|}{ Coeficiente de curtose } & 3,0109 & 6,4657 & 3,4060 & 2,8795 & 5,3016 \\
\hline \multicolumn{2}{|c|}{ Coeficiente assimetria } & 0,2242 & 0,9606 & 0,2950 & 0,3545 & 0,5696 \\
\hline \multicolumn{2}{|l|}{ Mínimo } & 0,0142 & 0,0077 & 0,0069 & 0,0072 & 0,0074 \\
\hline \multicolumn{2}{|l|}{ Máximo } & 0,0321 & 0,0207 & 0,0172 & 0,0198 & 0,0335 \\
\hline \multicolumn{2}{|l|}{ Média } & 0,0233 & 0,0116 & 0,0116 & 0,0148 & 0,0173 \\
\hline \multicolumn{2}{|l|}{ Mediana } & 0,0230 & 0,0115 & 0,0114 & 0,0148 & 0,0172 \\
\hline \multicolumn{2}{|l|}{ Moda } & 0,0221 & 0,0111 & 0,0113 & 0,0145 & 0,0154 \\
\hline \multicolumn{2}{|l|}{ Variância da amostra } & $1,16 \cdot 10^{-05}$ & $2,9 \cdot 10^{-06}$ & $2,48 \cdot 10^{-06}$ & $6,16 \cdot 10^{-06}$ & $1,5 \cdot 10^{-05}$ \\
\hline \multicolumn{2}{|l|}{ Desvio-padrão } & 0,0034 & 0,0017 & 0,0015 & 0,0024 & 0,0038 \\
\hline \multicolumn{2}{|l|}{ Erro-padrão } & 0,00024 & 0,00012 & 0,00011 & 0,00017 & 0,00027 \\
\hline \multicolumn{2}{|c|}{ IC $\mathrm{p}<0,005$ limite superior } & 0,02377 & 0,01183 & 0,01182 & 0,01514 & 0,01783 \\
\hline \multicolumn{2}{|c|}{ IC $\mathrm{p}<0,005$ limite inferior } & 0,02282 & 0,01136 & 0,01138 & 0,01445 & 0,01676 \\
\hline
\end{tabular}

Tabela 3 - Resultados das análises de regressão das frequências não acumuladas do peso de sementes de cinco plantas daninhas (Euphorbia heterophylla, Commelina benghalensis, Bidens pilosa, Cenchrus echinatus e Leonotis nepetaefolia), utilizando o modelo de Gompertz, bem como as médias, modas e medianas (g). Botucatu-SP, 2011

\begin{tabular}{|c|c|c|c|c|c|c|}
\hline \multirow{2}{*}{\multicolumn{2}{|c|}{ Modelo }} & \multicolumn{5}{|c|}{ Espécie } \\
\hline & & E. heterophylla & C. benghalensis & B. pilosa & C. echinatus & L. nepetaefolia \\
\hline \multirow{3}{*}{$\begin{array}{c}\text { Estimativas dos } \\
\text { parâmetros }\end{array}$} & A & 4,6052 & 4,6052 & 4,6052 & 4,6052 & 4,6052 \\
\hline & $\mathrm{B}$ & $-5,1707$ & $-5,1894$ & $-3,0987$ & $-2,7665$ & $-3,7530$ \\
\hline & $\mathrm{C}$ & 754,5300 & $2.656,5000$ & $2.379,4300$ & 621,8300 & $4.340,4400$ \\
\hline \multicolumn{2}{|l|}{$\mathrm{R}^{2}$} & 0,9844 & 0,9858 & 0,9934 & 0,9973 & 0,9828 \\
\hline \multicolumn{2}{|c|}{ Coeficiente de curtose } & 2,4306 & 3,4944 & 2,5965 & 2,6103 & 2,5027 \\
\hline \multicolumn{2}{|c|}{ Coeficiente assimetria } & $-0,1034$ & 0,2841 & 0,3026 & 0,4058 & 0,3016 \\
\hline \multicolumn{2}{|l|}{ Mínimo } & 0,0039 & 0,0012 & 0,0005 & 0,0015 & 0,0005 \\
\hline \multicolumn{2}{|l|}{ Máximo } & 0,0105 & 0,0038 & 0,0027 & 0,0104 & 0,0016 \\
\hline \multicolumn{2}{|l|}{ Média } & 0,0074 & 0,0021 & 0,0015 & 0,0053 & 0,0010 \\
\hline \multicolumn{2}{|l|}{ Mediana } & 0,0074 & 0,0021 & 0,0015 & 0,0049 & 0,0010 \\
\hline \multicolumn{2}{|l|}{ Moda } & 0,0081 & 0,0021 & 0,0013 & 0,0048 & 0,0009 \\
\hline \multicolumn{2}{|l|}{ Variância da amostra } & $1,99 \cdot 10^{-06}$ & $1,96 \cdot 10^{-07}$ & $2,22 \cdot 10^{-07}$ & $3,33 \cdot 10^{-06}$ & $6,26 \cdot 10^{-08}$ \\
\hline \multicolumn{2}{|l|}{ Desvio-padrão } & 0,0014 & 0,00044 & 0,00047 & 0,00182 & 0,00025 \\
\hline \multicolumn{2}{|l|}{ Erro-padrão } & $9,96 \cdot 10^{-06}$ & $3,13 \cdot 10^{-05}$ & $3,33 \cdot 10^{-05}$ & 0,00012 & $1,77 \cdot 10^{-05}$ \\
\hline \multicolumn{2}{|c|}{ IC $\mathrm{p}<0,005$ limite superior } & 0,00760 & 0,00216 & 0,00156 & 0,00555 & 0,00104 \\
\hline \multicolumn{2}{|c|}{ IC $\mathrm{p}<0,005$ limite inferior } & 0,00720 & 0,00204 & 0,00143 & 0,00505 & 0,00096 \\
\hline
\end{tabular}


quanto à variância, ao desvio-padrão da amostra e ao erro-padrão (Tabela 1) quando comparadas às de $B$. decumbens. Ao se observar o valor da curtose, que representa o grau de achatamento de uma curva de distribuição, tem-se o maior coeficiente para $B$. plantaginea - condição associada à maior concavidade da curva da frequência não acumulada. O valor do parâmetro "c" do modelo de Gompertz está diretamente relacionado com a curtose, sendo mais uniforme a distribuição com o aumento do parâmetro.

As relações entre o tamanho da semente, o número de sementes produzidas e o sucesso da sobrevivência são apontadas como elos que explicam a abundância e a dinâmica das espécies nas diversas tipologias vegetais. De acordo com Jakobsson \& Eriksson (2000), essas relações são exemplos da direta relação entre a estratégia evolucionária das espécies e a teoria da estrutura das comunidades vegetais. O tamanho das sementes está relacionado também com a uniformidade do estande das plantas e a produção de sementes ou grãos (Fantinatti et al., 2001).

Na Figura 2 estão apresentados os dados das frequências não acumuladas em função do peso de sementes do gênero Ipomoea. Para as cinco espécies estudadas, a assimetria foi positiva; assim, a média e a mediana estão à direita da moda, apresentando valores superiores ao desta. Os valores modais foram de 0,0221 g, 0,0154 g, 0,0145 g, 0,0113 g e $0,0111 \mathrm{~g}$, respectivamente, em ordem decrescente, para o peso de sementes de Ipomoea nil, I. purpurea, I. hederifolia, I. quamoclit e I. grandifolia.

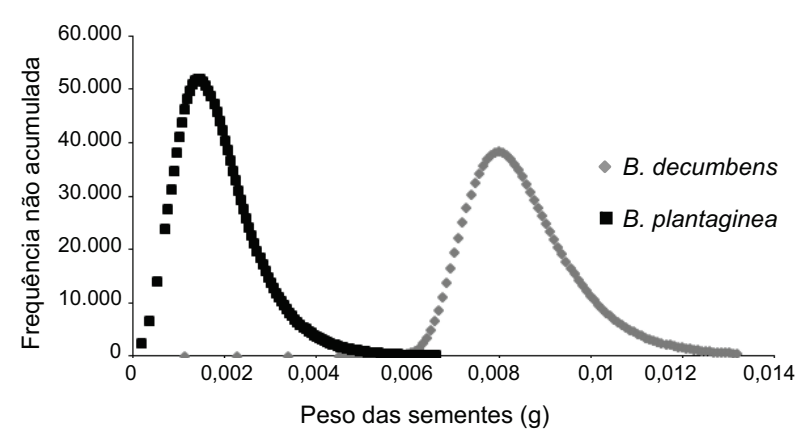

Figura 1 - Frequências não acumuladas em função do peso de sementes (g) de algumas plantas daninhas do gênero Brachiaria. Botucatu-SP, 2011.

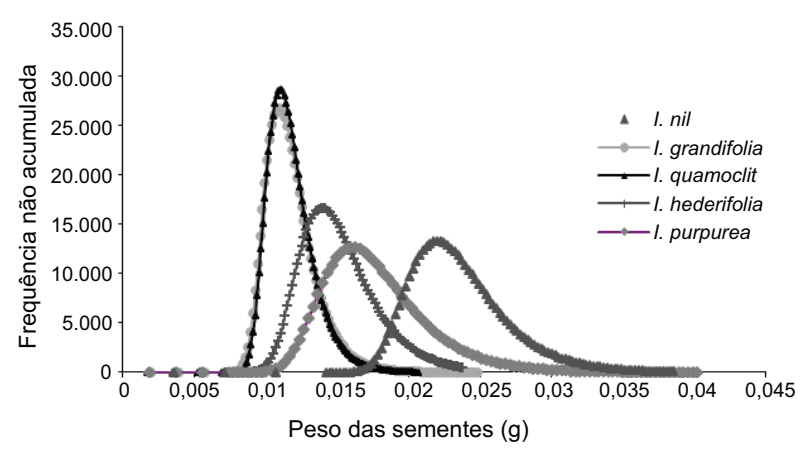

Figura 2 - Frequências não acumuladas em função do peso de sementes (g) de algumas plantas daninhas do gênero Ipomoea. Botucatu-SP, 2011

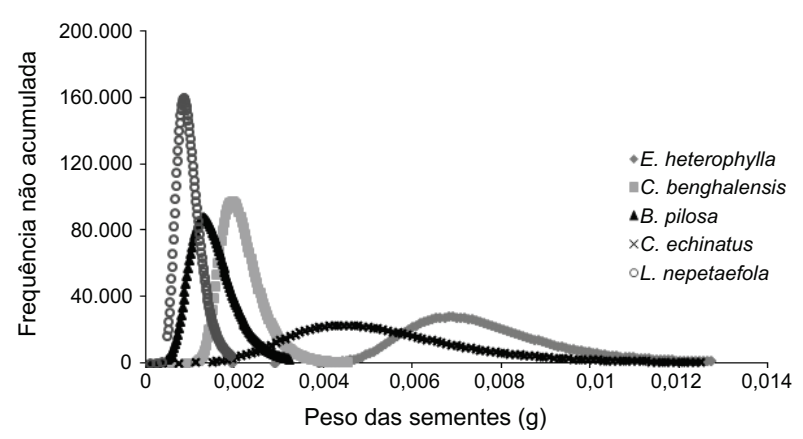

Figura 3 - Frequências não acumuladas em função do peso de sementes (g) das plantas daninhas Euphorbia heterophylla Commelina benghalensis, Bidens pilosa, Cenchrus echinatus e Leonotis nepetaefolia. Botucatu-SP, 2011.

Como a assimetria é positiva, as curvas de regressão têm tendência a subir rapidamente e descer de forma mais lenta. Ipomoea grandifolia e Ipomoea quamoclit apresentaram comportamento bastante similar e homogêneo, com concavidades maiores em relação às demais curvas de distribuição das frequências, demonstrando menor variação do tamanho das sementes formadas. Ipomoea quamoclit, I. grandifolia, I. hederifolia, I. nil e I. purpurea mostraram valores crescentes de variância, desvio-padrão e erro-padrão, haja vista os dados relativos apresentados na Tabela 2.

O tamanho da semente adotado por cada espécie representa, provavelmente, um compromisso entre as necessidades exigidas para a dispersão, as quais favorecem sementes pequenas, e as necessidades para o estabelecimento das mudas, as quais favorecem sementes grandes. Essa situação ambígua 
justifica um polimorfismo do tamanho das sementes. Para essas espécies, a estratégia de maior sucesso privilegia o tamanho em vez da quantidade de sementes.

Na Figura 3 estão apresentados os dados das frequências não acumuladas em função do peso de sementes das plantas daninha: Euphorbia heterophylla, Commelina benghalensis, Bidens pilosa, Cenchrus echinatus e Leonotis nepetaefolia. Nesse grupo, das cinco espécies, apenas Euphorbia heterophylla apresentou assimetria negativa $(-0,1034)$. Já para as espécies C. benghalensis, B. pilosa, C. echinatus e $L$. nepetaefolia, a assimetria foi positiva, com valores de $0,2841,0,3026,0,4058$ e 0,3016, respectivamente, destacando a maior variabilidade para sementes grandes (Tabela 3).

As espécies L. nepetaefolia e C. echinatus apresentaram os menores e os maiores valores de variância, desvio-padrão e erro-padrão, bem como o maior e o menor valor para o parâmetro "c" do modelo de Gompertz (maior concavidade da curva de distribuição das frequências), sendo caracterizadas, portanto, como as que possuem maior e menor uniformidade de tamanho de sementes, respectivamente, quando comparadas às demais desse grupo.

Na Tabela 3 encontram-se as frequências dos pesos das sementes representados pela moda nas equações de frequência não acumulada do modelo, os quais foram de $0,0009 \mathrm{~g}$, $0,0013 \mathrm{~g}, 0,0021 \mathrm{~g}, 0,0048 \mathrm{~g}$ e $0,0081 \mathrm{~g}$, respectivamente para L. nepetaefolia, B. pilosa, C. benghalensis, C. echinatus e E. heterophylla. Analisando a amplitude no peso das sementes, C. echinatus apresentou a maior variação de tamanho, entre a maior e a menor, com valor da ordem de sete vezes. $E$. heterophylla e $C$. benghalensis apresentaram suas sementes maiores 2,5 vezes mais pesadas que as menores; para $B$. pilosa, a variação entre a menor e a maior semente foi de cinco vezes.

Os resultados indicam que não há como se referir ao peso de sementes das espécies de plantas daninhas estudadas considerandose apenas a média dessa característica, em razão da grande variação que pode ser encontrada. A grande variação dessa característica pode estar associada, também, a variações nos padrões de emergência.

A porcentagem de emergência acumulada em relação à profundidade, para os três tamanhos de sementes de I. purpurea e B. decumbens, é apresentada nas Figuras 4 e 5.

Para a espécie I. purpurea, houve diferença na emergência das plântulas em função do tamanho das sementes (Figura 4). Sementes pequenas obtiveram menor porcentagem de emergência quando comparadas às sementes médias e grandes, sendo que estas apresentaram comportamento semelhante entre si. A porcentagem de emergência acumulada na profundidade de $10 \mathrm{~cm}$ foi de 25,40 e $41 \%$ para sementes pequena, média e grande, respectivamente (Figura 4).

Oliveira et al. (2005) afirmam que, dentro de um mesmo lote de sementes, aquelas

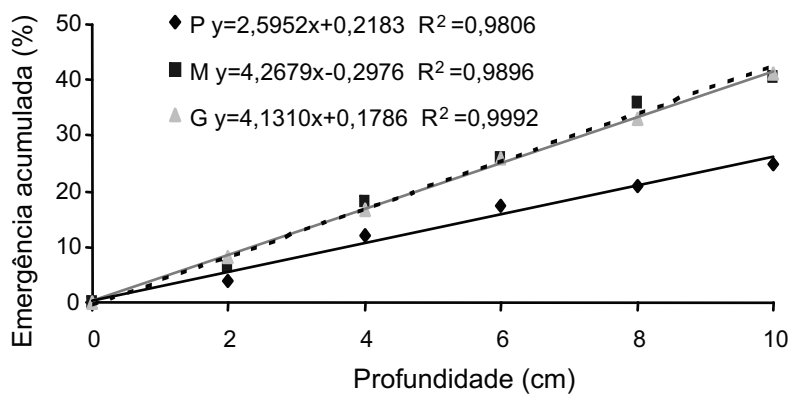

Figura 4 - Relação da emergência acumulada (em porcentagem da quantidade semeada) com a profundidade aos 18 dias após semeadura dos três tipos de sementes de Ipomoea purpurea. Botucatu-SP, 2011.

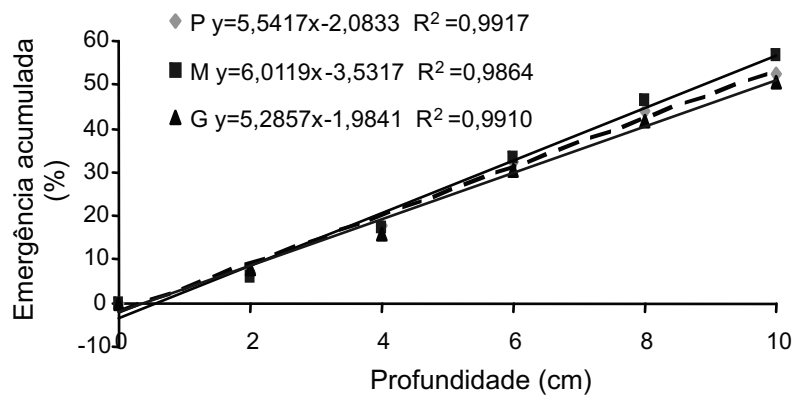

Figura 5 - Relação da emergência acumulada (em porcentagem da quantidade semeada) com a profundidade aos 18 dias após semeadura dos três tipos de sementes de Brachiaria decumbens. Botucatu-SP, 2011. 
denominadas pequenas podem apresentar menor emergência e vigor de plântulas do que as sementes consideradas médias e grandes. A maior quantidade de reserva aumenta a probabilidade de sucesso no estabelecimento da plântula, pois permite a sobrevivência por maior tempo em condições ambientais desfavoráveis. Quanto à espécie B. decumbens, o comportamento da emergência acumulada nas profundidades de semeadura utilizadas foi semelhante para os três tamanhos de classificação de sementes estudados (Figura 5).

Ao analisar o IVE para os diferentes tamanhos de sementes de I. purpurea nas cinco profundidades de semeadura, o maior índice ocorreu aos $4 \mathrm{~cm}$ de profundidade para as sementes pequenas, $8 \mathrm{~cm}$ para sementes médias e 6,8 e $10 \mathrm{~cm}$ para sementes grandes (Figura 6). A capacidade de emergência aumenta com o tamanho da semente; quanto maior a semente, maior é a profundidade em que as plântulas conseguem emergir, por estas apresentarem maior tecido de reserva para ultrapassar todas as barreiras físicas do solo (King, 1979).

Trabalhos realizados por Toledo et al. (1993) com X. strumarium constataram maiores indices de velocidade de emergência em menores profundidades do solo, com quase $70 \%$ de emergência. Neste estudo, situação similar foi observada apenas com as sementes pequenas de I. purpurea (Figura 6).

Resultados obtidos por Dias Filho (1996), estudando Ipomoea asarifolia, e por Toledo et al. (1993), estudando Xanthium strumarium, mostram que as plântulas das espécies avaliadas emergiram de profundidades superiores a $9 \mathrm{~cm}$ - fato esse também observado neste estudo. As sementes grandes de I. purpurea apresentaram maior IVE quando semeadas a $10 \mathrm{~cm}$ de profundidade (Figura 6G). Yamashita et al. (2005) afirmam que sementes de fedegoso apresentam, também, boa capacidade de emergência de plântulas quando semeadas em maiores profundidades.

Para B. decumbens (Figura 7M e G), as sementes médias e grandes apresentaram superioridade estatística do IVE quando semeadas a $6 \mathrm{~cm}$ de profundidade. Não houve diferenças significativas no IVE para sementes classificadas como pequenas, porém observou-se tendência de superioridade do índice para a profundidade de $6 \mathrm{~cm}$ (Figura 7P).

Dessa forma, para as condições ambientais em que as sementes utilizadas foram produzidas e manipuladas neste estudo, conclui-se que para a espécie I. purpurea não há como se referir ao peso de sementes considerando apenas o valor médio destas, visto que as sementes pequenas, médias e grandes
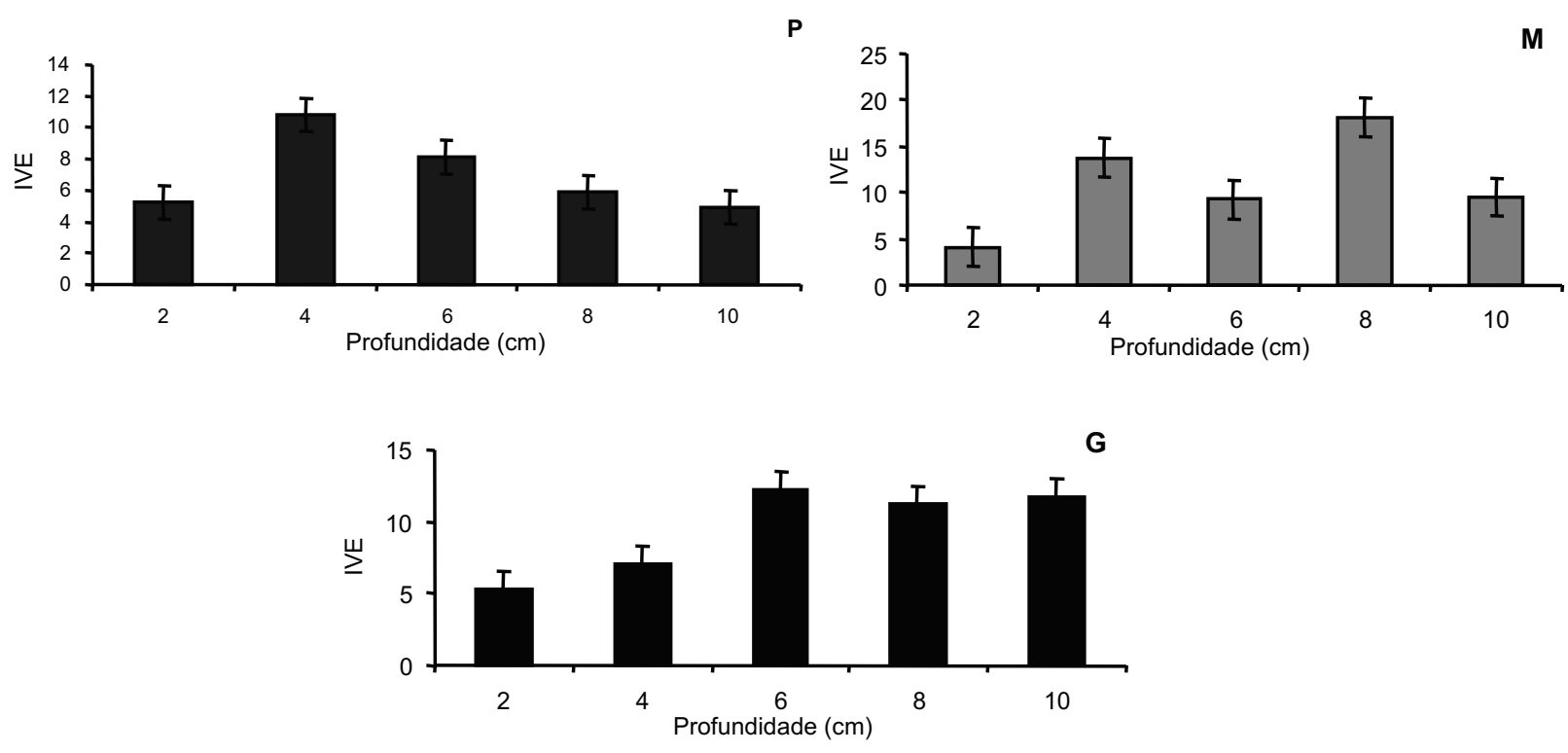

Figura 6 - Índice de velocidade de emergência (IVE) para as profundidades de 2, 4, 6, 8 e $10 \mathrm{~cm}$ de Ipomoea purpurea . P = semente pequena, $\mathrm{M}=$ semente média e $\mathrm{G}=$ semente grande. Botucatu-SP, 2011 

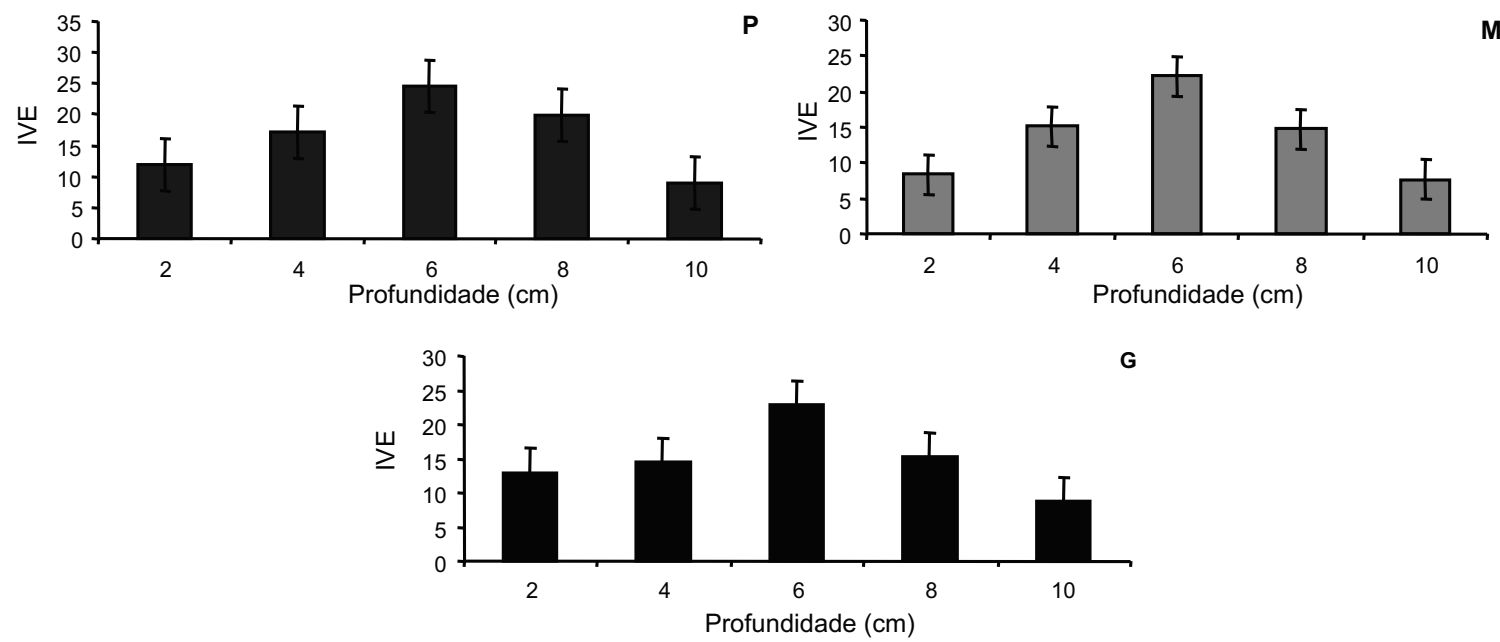

Figura 7 - Índice de velocidade de emergência (IVE) para as profundidades de 2, 4, 6, 8 e $10 \mathrm{~cm}$ de Brachiaria decumbens $\mathrm{P}=$ semente pequena, $\mathrm{M}=$ semente média e $\mathrm{G}=$ semente grande. Botucatu-SP, 2011.

mostraram diferenças no comportamento de emergência - situação essa não verificada para B. decumbens.

\section{LITERATURA CITADA}

ANDRADE, R. V. et al. Influência do tamanho e da forma da semente de dois híbridos de milho na qualidade fisiológica durante o armazenamento. R. Bras. Sementes, v. 20, n. 2 , p. 363-366, 1998.

BALBINOT JR., A. A. et al. Predação de sementes de plantas daninhas em áreas cultivadas. Ci. Rural, v. 32, n. 4, p. 707-714, 2002.

BEAN, E. W. Seed quality: its variation, control and importance in breeding and varietal assessment. Ann. Report Weish. Plant Breeding Stat., p. 194-208, 1973.

BRIGHENTI, A. M.; VOLL, E.; GAZZIERO, D. L. P. Biologia e manejo do Cardiospermun halicacabum. Planta Daninha, v. 21, n. 2, p. 229-237, 2003.

DIAS FILHO, M. B. Germination and emergence of Stachytarpheta cayennensis and Ipomoea asarifolia. Planta Daninha, v. 14, n. 2, p. 118-126, 1996

FANTINATTI, J. B.; HONÓRIO, S. L.; RAZERA, L. F. Qualidade de sementes de feijoeiro (Phaseolus vulgaris L.) de diversas densidades, obtidas em mesa gravitacional. Informativo ABRATES, v. 11, n. 2, p. 83, 2001.

FAUSEY, J. C.; RENNER, K. A. Germination, emergence, and growth of giant foxtail (Setaria faberi) and fall panicum (Panicum dichotomiflorum). Weed Sci., v. 45, n. 3, p. 423-425, 1997.
FONTES, J. R. A. Considerações sobre o banco de sementes de plantas daninhas no solo (2005). Disponível em: $<$ http://www.agronline.com.br/artigos/ artigo.php?id=220>. Acesso em: 31 jan. 2009

GHORBANI, R.; SEEL, W.; LEIFERT, C. Effects of environmental factors on germination and emergence of Amaranthus retroflexus. Weed Sci., v. 47, n. 5, p. 505-510, 1999.

GUIMARÃES, S. C.; SOUZA, I. F.; PINHO, E. V. R. V. Emergência de Tridax procumbens em função de profundidade de semeadura, do conteúdo de argila no substrato e da incidência de luz na semente. Planta Daninha, v. 20, n. 3, p. 413-419, 2002.

JAKOBSSON, A.; ERIKSSON, O. A comparative study of seed number, seed size, seedling size and recruitment in grassland plants. Oikos, v. 88, n. 3, p. 494-502, 2000.

KING, M. W.; ROBERTS, E. H. The storage of recalcitrant seeds: achievements and possible approaches Rome: IBPGR, 1979. 22 p.

OLIVEIRA JR., R. S.; DELISTOIANOV, F. Profundidade de semeadura e métodos de quebra de dormência afetando a germinação e a emergência de Desmodium purpureum (Mill) Fawc. et Rend (Leguminosae Papilionoideae). R. Bras. Bot. v. 19, n. 2 , p. $221-225,1996$

OLIVEIRA, I. V. M. et al. Influência do tamanho da semente na emergência das plântulas de longan (Dimocarpos longan) R. Bras. Frutic., v. 27, n. 1, p. 171-172, 2005.

ROSENTHAL, M. D. A. et al. Toxicidade do herbicida Smetolachlor em plantas de milho provenientes de sementes com diferentes formatos e dimensões. Planta Daninha, v. 24, n. 2, p. 319-327, 2006. 
SHEN, J. et al. Effect of environmental factors on shoot emergence and vegetative growth of alligatorweed (Alternanthera philoxeroides). Weed Sci., v. 53, n. 4, p. 471-478, 2005.

SOLBRIG, O. T.; SIMPSON, B. B. Components of regulation of a population of dandelions in Michigan. J. Ecol., v. 62, n. 2 , p. $473-486,1974$

SOUZA, F. H. D. Características físicas das sementes de Calopogonium mucunoides Desv. associadas à qualidade fisiológica e ao padrão de absorção de água: I. Tamanho. R. Bras. Sementes, v. 18, n. 1, p. 33-40, 1996

THOMPSON, K.; BAND, S. R.; HODGSON, J. G. Seed size and shape predict persistence in soil. Funct. Ecol., v. 7, n. 2, p. 236-241, 1993.
TOLEDO, R. E. B.; KUVA, M.; ALVES, P. L. C. A. Fatores que afetam a germinação e a emergência de Xanthium strumarium L.: dormência, qualidade de luz e profundidade de semeadura. Planta Daninha, v. 11, n. 1/2, p. 15-20, 1993.

VELINI, E. D. Estudos e desenvolvimento de métodos experimentais e amostrais adaptados à matologia. 1995 250 f. Tese (Doutorado em Agronomia) - Universidade Estadual Paulista Júlio de Mesquita Filho, Jaboticabal, 1995

WERNER, P. A.; PLATT, W. J. Ecological relationships of co-occurring goldenrods (Solidago: Compositae). Am. Natur., v. 110 , n. 976 , p. $959-971,1976$

YAMASHITA, O. M. et al. Efeito de profundidade de semeadura na emergência de picão-preto (Bidens pilosa) e fedegoso (Cassia occidentalis). R. Ci. Agro-Amb., v. 3, n. 1, p. 84-91, 2005. 